\title{
LA AUSENCIA DE LA MADRE Y LA ASERSIÓN DE LA SUBJETIVIDAD EN NADA DE CARMEN LAFORET
}

\author{
Victoria Calmes \\ University of Wisconsin
}

El tema central de la novela Nada de Carmen Laforet es la visión de la vida en la época de la posguerra española desde la perspectiva de una joven adolescente, Andrea. Desde que recibió el premio Nadal en 1944, la novela ha sido objeto de múltiples análisis. Este estudio analiza los aspectos de asersión de la subjetividad del personaje central. Algunos críticos, como Marsha Collins o Michael Thomas, han debatido los aspectos de la evolución del personaje como emancipación femenina o como Bildungsroman, analizando el desarrollo de la protagonista y su paso hacia la madurez'. Mariana Petrea, en su estudio "La promesa de futuro: La dialéctica de la emancipación femenina en Nada de Carmen Laforet", analiza los aspectos de emancipación del personaje central, Andrea, basados en el cambio de la protagonista como narradora de la novela y en el poder de la amistad. Por otra parte, otros críticos como Barry Jordan en "Laforet's Nada as a Female Bildung?", no están de acuerdo con la visión de la novela como Bildungsroman. Alicia Andreu discute en su artículo "Huellas textuales en el Bildungsroman de Andrea" las diferentes etapas en la formación de la protagonista y las pautas de su desarrollo desde su llegada a Barcelona, señalando los sustratos romántico y realista dentro del texto. Sin embargo, no está de acuerdo con la visión positiva del Bildungsroman y la adquisición del autoconocimiento. Por el contrario, en su opinión, el final está caracterizado por la ambigüiedad.

Este estudio tiene como propósito analizar el concepto de identidad del personaje central dentro de las pautas de la asersión de su subjetividad, pero está enfocado desde un punto de vista diferente de los estudios previamente citados. Demostraré que el deseo de individualidad o de cmancipación de la protagonista tiene su origen en una ausencia, la de la madre, foco central para el desarrollo del personaje principal. El intento de llenar este vacío maternal va a estar marcado por la imposibilidad de encontrar modelos que puedan sustituirla.

1.- Marsha Collins, "Carmen Laforet's Nada: Fictional Form and Search of Identity". Symposium 38.4 (1984-5): 298-310. Michael Thomas, "Symbolic Portals in Laforet's Nada". Revista Hispánica Moderna, 32 (1996): 43-55. 


\section{LA AUSENCIA DE LA MADRE Y LA ASERSIÓN DE LA SUBJETIVIDAD}

Muchos críticos han debatido el tema de la influencia del papel de la madre en el crecimiento e identidad del individuo. Nancy Chodorov en su libro The Reproduction of Mothering: Psychoanalysis and the Sociology of Gender; ha estudiado la importancia esencial de la figura de la madre desde las etapas más tempranas de crecimiento del individuo y en la formación de su subjetividad en relación a la imagen materna: «The continuity of (the mother's) care enables the infant to develop a self -a sense that "I am". [...] In a society where mothers provide nearly exclusive care and certainly the most meaningful relationship to the infant, the infant develops its sense of self mainly in relation with her» [La continuidad del cuidado de la madre hace posible que el/la niño/a desarrolle una identidad -un sentido de "yo soy". [...] En una sociedad donde las madres proveen un cuidado casi exclusivo y ciertamente la relación más significativa al niño/a, éste/a desarrolla un sentido de sí mismo principalmente en relación con ella] (77-78).

A causa de esta relación esencial desde las edades más tempranas, la ausencia de la madre tiene repercusiones dramáticas en la asersión de la subjetividad del individuo. Ésta es una idea central en Nada, cuya protagonista pierde a su madre desde niña y, como consecuencia, debe enfrentarse a una situación de abandono y desamparo que va a afectar la emergencia de su personalidad. Como ha señalado Hope Edelman en su libro Motherless Daughters: The Legacy of Loss, la falta de la figura de la madre tiene repercusiones negativas en el desarrollo de la identidad de la hija joven:

Unlike the adult, who experiences parent loss with a relatively intact personality, a girl who loses her mother during childhood or adolescence co-ops the loss into her emerging personality, where it then becomes a defining characteristic of her identity. From learning at an early age that close relationships can be impermanent, security ephemeral, and family capable of being redefined, the motherless daughter develops an adult insight while still a child but has only juvenile resources to help her cope.

[A diferencia del adulto, quien experimenta la pérdida del padre/madre con una personalidad relativamente intacta, una niña que pierde a su madre durante la infancia o adolescencia incorpora la pérdida a su personalidad emergente, donde se convierte en una característica que define su identidad. Como aprende desde edades tempranas que las relaciones cercanas pueden ser temporales, la seguridad efímera, y la familia puede ser redefinida, la hija que ha perdido a la madre desarrolla un discernimiento adulto mientras todavía es una niña, pero sólo tiene recursos juveniles para ayudarle a hacer frente a esta situación] (xxiv-xxv).

El personaje protagonista de Nada, Andrea, es una joven idealista que llega a Barcelona con el propósito de estudiar en la universidad y vivir con sus familiares. Andrea llega cargada de expectativas e ilusiones acerca de su nueva vida y de su libertad. Sin embargo, la impresión que recibe después de su llegada a la casa de la calle Aribau representa el polo opuesto de sus expectativas. La casa y la familia han sufrido el terrible impacto de la Guerra Civil española y nada es como Andrea recordaba en su niñez.

La ausencia de la madre es un tema clave para comprender el estado de soledad y abandono con el que tiene que enfrentarse Andrea durante el año de estancia en Barcelona. Desde el principio de la obra se hace mención a su orfandad y a los diferentes lugares y colegios donde había sido educada. La ausencia de sus padres y su condición de huérfana van a marcar la vida de Andrea desde su niñez. Como indica Barry Jordan: «Andrea's main problem and the stigma she has had to live with, is that she is an orphan. She is obsessed by a lack of origins and harbours a deep sense of inferiority and rejection» [El problema principal de Andrea y el estigma con el que ha tenido que vivir, es que es huérfana. Está obsesionada por una falta de orígenes y alberga un sentido profundo de inferioridad y rechazo] (Shifting 420).

Debido a la ausencia de la madre y a su condición de huérfana, Andrea va a buscar modelos que seguir y con los que encontrar una identificación positiva. Sin embargo, la búsqueda de modelos y la añoranza del "paraíso" de lo maternal se va a ver dificultada por la situación que encuentra a su llegada a Barcelona. 


\section{VICTORIA CALMES}

En Nada la idea de "paraíso" maternal se contrapone dramáticamente con imágenes y recursos simbólicos de la casa y de la familia que aparecen representados como "infierno". Esta situación tiene como resultado la imposibilidad de identificación con los miembros de su familia, dificultando su búsqueda de modelos.

Desde su llegada a Barcelona, Andrea experimenta las tensiones, los odios, las luchas y los insultos crueles que los miembros de la familia se dirigen constantemente. Son seres que se espían y critican, encontrando placer en hacer daño y mortificar a otras personas en su propia familia. Como Gloria le explica a Andrea: «Ya irás conociendo a cstas gentes; son terribles, ya verás... No hay nadie bueno aquí, como no sea por la abuelita, que la pobre está trastornada» (35). Son seres que han sufrido física y psíquicamente el terrible impacto de un conflicto bélico de tres años que había dividido con violencia y odios a las gentes del mismo país, ciudad e, incluso, de la propia familia.

La guerra aparece como un acontecimiento externo, como un telón de fondo del que no se hacen muchas referencias explícitas. Quizás esta falta de referencias sea debida a la censura impuesta por el régimen fanquista ${ }^{2}$. Sin embargo, la guerra y sus efectos en las personas y en las ciudades es un tema que está presente implícitamente durante toda la novela. Existe una marcada dicotomía entre el antes y el después del conflicto bélico, que en la novela aparece representada con elementos simbólicos maniqueístas. El pasado se ve como un "paraíso" en la memoria de Andrea, que guarda una memoria idílica de Barcelona en sus visitas antes de la Guerra Civil y recuerda con nostalgia las temporadas que pasaba con sus abuelos como las más emocionantes de su vida infantil.

Los recuerdos de la niñez de Andrea chocan violentamente con la realidad que encuentra a su llegada a Barcelona. A esa imagen de "paraíso" se le opone la imagen actual de "infierno" con toda una serie de elementos simbólicos de referencia a la muerte que caracterizan a los personajes de su familia. Andrea describe a su tío Juan con «la cara llena de concavidades, como una calavera» (14). Seguidamente aparecieron «varias mujeres fantasmales» (15). Una de ellas es la criada y «todo en aquella mujer parecía horrible y destrozado, hasta la verdosa dentadura que me sonreía» (15). La descripción de Gloria contribuye a esta visión fantasmal: «una mujer con la languidez de sábana colgada, que aumentaba la penosa sensación del conjunto» (15). Todas aquellas figuras cran «alargadas, quietas y tristes, como luces de un velatorio de pueblo» (15).

El inmenso contraste con la visión anterior de la ciudad de Barcelona y de su familia en el pasado y la realidad que encuentra a su llegada a Barcelona le produce una impresión tan fuerte que le hace dudar incluso de la realidad que está viendo, llegando a pensar que todo pudiera ser «una pesadilla» (13). Pero lo que Andrea observa ahora es el resultado de los sufrimientos, angustias y calamidades que estos personajes habían sufrido durante el período de la guerra y principios de la posguerra. Un claro ejemplo de la dialéctica entre el antes y el después de la guerra es la figura de la abuela. Para presentar la imagen anterior de este personaje, la narradora se sirve del recurso visual de un cuadro. Andrea observa con perplejidad la imagen de sus abuelos en este cuadro. Su abuela no era la viejecita pequeña y consumida que había visto al llegar, sino «una mujer de cara ovalada bajo el velillo de tul de un sombrero a la moda del siglo pasado. Sonreía suavemente, y la seda azul de su traje tenía una tierna palpitación» (21). La confrontación de esta imagen de la abuela en el cuadro con la visión actual que recibió al llegar a la casa produce de nuevo una impresión desoladora en Andrea: «Me complací en pensar que nada tenía que ver la joven del velo de tul con la pequeña momia irreconocible que me había abierto la puerta» (énfasis mío, 23). De nuevo, la descripción de este personaje tiene connotaciones de decrepitud y de muerte.

2.- Stacey Dolgin Casado ha señalado algunos aspectos de la censura en su artículo "Structure as Meaning in Carmen Laforet's Nada: A Case of Self-Censorship", p. 355. 


\section{LA AUSENCIA DE LA MADRE Y LA ASERSIÓN DE LA SUBJETIVIDAD}

Las consecuencias de la Guerra Civil se aprecian igualmente en la casa y en la ciudad de Barcelona. En la descripción que Andrea hace de la casa a su llegada a la calle Aribau existe un marcado contraste entre el pasado y el presente. El recuerdo idílico de la casa se convierte ahora en una realidad descrita con tonos de lugar decrépito e infernal. Del cuarto de baño Andrea recuerda: «Parecía una casa de brujas aquel cuarto de baño. Las paredes tiznadas conservaban la huella de manos ganchudas, de gritos de desesperanza" (17). Aparte de la imagen diabólica de la "casa de brujas", la casa funciona como un microcosmos de la sociedad de la posguerra y de las angustias y penalidades que la gente sufría ${ }^{3}$. Andrea observa todo esto con terror. La figura de la protagonista como una muchacha sola y huérfana sirve para agudizar dramáticamente el contraste entre su imagen inocente y desvalida y el mundo infernal al que se tiene que enfrentar y con el que tendrá que convivir durante un año. Sus expectativas y sus ilusiones antes de llegar a Barcelona se habían convertido en algo semejante a una pesadilla ya la primera noche en la casa. La descripción de este momento nos revela más elementos simbólicos de la casa como lugar de muerte o infierno:

Tuve súbitas ganas de llorar [...] hasta aquel momento de entrar en este ambiente de gente y de muebles endiablados. Tenía miedo de meterme en aquella cama parecida a un ataíd. Creo que estuve temblando de indefinibles terrores cuando apagué la luz. (19, énfasis mío).

Estas imágenes negativas de la casa como un microcosmos social son una proyección simbólica de la situación que sufría la ciudad de Barcelona en la época de la posguerra. La tía Angustias resume este contexto diciendo a Andrea: «La ciudad es un infierno. Y en toda España no hay ciudad que se parezca más a un infierno que Barcelona» (25).

A causa de este ambiente negativo y de la ausencia de la madre, la asersión de la subjetividad para Andrea tiene que realizarse buscando otros medios de identificación para enfrentarse a la ardua tarea de definirse como individuo y, más importante, como mujer. Como ha indicado Edelman:

Early loss is a maturing experience, forcing a daughter to age faster than her peers at both cognitive and behavioral levels. [ . . ] When a mother's death also means the loss of the consistent, supportive family system that once supplied her with a secure home base, she then has to develop her self-confidence and self-esteem through alternative means. Without a mother or mother-figure to guide her, a daughter also has to piece together a female self-image on her own. (xxv)

[Una pérdida temprana es una experiencia que hace madurar, forzando a la hija a crecer más rápido que sus compañeros a niveles de conocimiento y de comportamiento. [...] Cuando la muerte de la madre también conlleva la pérdida de un sistema familiar estable y protector que antes le había suministrado una base de hogar segura, entonces ella tiene que desarrollar una confianza en sí misma y una estima propia por medios alternativos. Sin una madre o una figura maternal que la guíe, una hija también tiene que completar una imagen femenina por sí misma.] (xxv)

En su búsqueda de posibles modelos de identificación en la casa Aribau, es el personaje de la tía Angustias el que se otorga la responsabilidad de educar a Andrea, intentando llegar a ser una figura que sustituya a la de la madre. Sin embargo, esto supone un intento fallido. La primera impresión que Andrea recibe de Angustias va a ser premonitoria de su carácter real. Andrea recuerda su voz seca, resentida y el desprecio en su gesto. Desde su primera conversación, Angustias aparece como una mujer autoritaria, sumida en una idea de religiosidad sin caridad ni amor. Las ilusiones de libertad de Andrea a su llegada a Barcelona se ven truncadas inmediatamente cuando se hace

3.- J. Kronik estudia este simbolismo de la casa y de los ambientes cerrados en relación al ambiente político y social en la época de la posguerra española en su artículo "Nada y el texto asfixiado: Proyección de una estética". Robert C. Spires analiza los aspectos simbólicos negativos en la novela en su artículo "Nada y la paradoja de los signos negativos". 


\section{VICTORIA CALMES}

obvio el autoritarismo matriarcal que Angustias intenta imponer sobre Andrea. Por lo tanto, Andrea no encuentra el refugio de calor maternal que la imagen de la madre representa sino lo contrario. Angustias aparece caracterizada con sentimientos de egoísmo y de falta de caridad, haciendo reproches constantes al estado de orfandad de Andrea. Ante la circunstancia del deseo de Andrea de estudiar en la universidad, Angustias le reprocha: «Bueno, yo no me opongo, pero siempre que sepas que todo nos lo deberás a nosotros los parientes de tu madre. Y que gracias a nuestra caridad lograrás tus aspiraciones» (26).

En este ambiente hostil de la casa, Andrea encuentra a uno de los familiares más fascinante que el resto. El personaje de Román aparece a los ojos de la protagonista como un ser cargado de fuerza y misterio. Andrea ve la crueldad y el cinismo con que trata a su hermano Juan y al resto de las personas en la casa, pero se siente atraída y fascinada por la faceta artística del personaje. Esto va a ser una característica común con otras obras como La isla y los demonios de Carmen Laforet, y Entre visillos de Carmen Martín Gaite. Las jóvenes huérfanas protagonistas buscan una amistad o una identificación con un hombre más maduro, por el que llegan a sentir fascinación al percibir sus cualidades artísticas. Esta fascinación o enamoramiento platónico acaba en decepción en todos los casos.

En el caso de Román, la cualidad artística que fascina a Andrea cs la capacidad de tocar el violín y el piano. Aunque siente cierto recelo hacia Román, su faceta artística la atrae tremendamente:

Yo no lo dudaba: me parecía ver en Román un fondo inagotable de posibilidades. En el momento en que, de pie junto a la chimenea, empezaba a pulsar el arco, yo cambiaba completamente. Desaparecían mis reservas, la ligera capa de hostilidad contra todos que se me había ido formando. Mi alma, extendida como mis propias manos juntas, recibía el sonido como una lluvia en tierra áspera. Román me parecía un artista maravilloso y único. Iba hilando en la música una alegría tan fina que traspasaba los límites de la tristeza (41).

El carácter de Román, como los del resto de la familia, aparece marcado por las secuelas de la Guerra Civil. Andrea empieza a conocer más a Román y ver sus facetas más negativas y llega a la conclusión de la imposibilidad de depositar su confianza en él. Román le muestra un pesimismo trascendental y aparece trastornado y desequilibrado, sobre todo en su afán de control y mortificación de otras personas. Román le explica este poder a Andrea: «¿Tú no te has dado cuenta de que yo los manejo a todos, de que dispongo de sus nervios, de sus pensamientos...? Tú sabes muy bien hasta qué punto Juan me pertenece, hasta qué punto se arrastra tras de mí, hasta qué punto le maltrato» (91).

Román muestra características diabólicas en la búsqueda de placer al causar sufrimiento a los demás y en su capacidad de controlar los sentimientos y jugar con las emociones de las personas en su familia. Andrea percibe estas cualidades y se desilusiona con Román. La iconografía de la casa y de los personajes como "infierno" se repite con Román cuando Andrea indica que «la risa de Román me alcanzaba como la mano huesuda de un diablo que me cogiera la punta de la falda» (92, énfasis mío).

Ante las experiencias negativas con los personajes de la casa de la calle Aribau, Andrea reconoce la imposibilidad de identificación con ninguno de los personajes de su familia. La muchacha siente soledad y se encuentra perdida, sintiendo un anhelo real de compañía humana. Al no tener el consuelo del regazo maternal su búsqueda del cariño, la comprensión y el amor de las personas se va a convertir en una constante en su vida.

Andrea consigue escapar de este mundo "infernal" de la calle Aribau y formar otro mundo totalmente diferente con sus amigos de la universidad. Es especialmente significativo el personaje de Ena y la amistad que en ella encuentra. Ena se va a convertir en un apoyo para Andrea y le va a conferir la sensación se sentirse importante y querida por primera vez desde su llegada a Barcelona. 


\section{LA AUSENCIA DE LA MADRE Y LA ASERSIÓN DE LA SUBJETIVIDAD}

La familia de Ena representa el polo contrario de la familia de la calle Aribau. Son seres rubios, elegantes y amables. Aparte de las diferencias de clase social, de nuevo los elementos simbólicos presentan una oposición maniqueísta entre infierno y paraíso. La madre de Ena, Margarita, es un personaje que atrae a Andrea desde el principio. Ella ha encontrado una razón que satisface su existencia en la experiencia de la maternidad. El nacimiento de su hija Ena supuso un cambio radical en sus prioridades, volviendo toda su dedicación hacia su hija. Como indica Elizabeth Ordóñez:

Ena confers upon her mother an existencial significance which to the latter was heretofore unknown. With the birth of the daughter, the mother learns the meaning of renunciation, comprehension, friendship and tenderness... For Ena's mother maternity functions as the door which opens unknown horizons and allows her to free herself from her narrow selfishness.

[Ena confiere a su madre un significado existencial que hasta ahora la madre no había conocido. Con el nacimiento de su hija, la madre aprende el significado de la renuncia, la comprensión, la amistad y la ternura... Para la madre de Ena la maternidad funciona como la puerta que abre horizontes desconocidos y le permite liberarse de su egoísmo estrecho] (69).

Para Andrea, es esencial buscar un sentido de identidad no sólo como persona sino también como mujer, sin tener la identificación primaria de la figura de la madre. En este sentido, recibe ideas de Angustias sobre la mujer y su lugar en la sociedad. Angustias describe el matrimonio como la única salida moral y deseable para la mujer, aparte del convento. Como indica Roberta Johnson: «Angustias stands for the conservative values of Spanish society in which the only alternative for women who do not marry is to enter a convent» [Angustias representa los valores conservadores de la sociedad española en la que la única alternativa para las mujeres que no se casan es el convento] (49). El matrimonio se percibe como salvación y como situación ideal para el futuro de la mujer en sociedad. Barry Jordan indica que: «Marriage as safe heaven from emotional turmoil or family pressures has already surfaced in the Aribau household, where three of the four sisters have married simply to escape the repressions of a strict bourgeois household» [El matrimonio como salvación de la agitación emocional o de la presión familiar ha aparecido ya en la casa de Aribau, donde tres de las cuatro hermanas se han casado simplemente para escapar la represión de un hogar burgués represivo] (98 Narrators).

Para Andrea, es esencial buscar un sentido de identidad sin tener la identificación primaria de la figura de la madre. Esto conlleva una crisis de identidad. Andrea no sabe realmente quién es o bajo qué parámetros definirse como persona y, más importante, como mujer. La imagen del espejo tiene connotaciones simbólicas de asersión de la subjetividad:

Al levantarme de la cama vi que en el espejo de Angustias estaba toda mi habitación llena de un color de seda gris, y allí mismo, una larga sombra. Me acerqué y el espectro se acercó conmigo. Al fin alcancé a ver mi propia cara desdibujada sobre el camisón de hilo. Un camisón de hilo antiguo -suave por el roce del tiempo- cargado de pesados encajes, que muchos años atrás había usado mi madre. Era una rareza estarme contemplando así, casi sin verme, con los ojos abiertos (213-4).

Es importante señalar los aspectos de temporalidad en este pasaje, donde se contraponen el pasado y el presente mediante las cosas grises y la ropa vieja de la madre muerta con la juventud de la hija. La crisis de identidad de Andrea se simboliza en el hecho de contemplarse sin verse. Lo que ella considera un "espectro" es lo que representa su imagen real, con la que finalmente tiene que identificarse. Es importante señalar el hecho de que Andrea se mira al espejo buscando su propia imagen, pero en esta situación lleva puesto el camisón de su madre, entonces su imagen en el espejo refleja, en cierto modo, la imagen de la madre, que ha estado ausente durante toda su vida. La idea de la madre ausente repercute de una manera más íntima en esta época adolescente y vulnerable del desarrollo de la subjetividad de Andrea. En el momento de definirse ella misma como mujer, la añoranza de la figura de la madre, de su proximidad y su consejo es más evidente. La imagen que Andrea ve en el espejo refleja simbólicamente la añoranza y la necesidad de encontrar esa figura materna en esos momentos de duda existencial y de inseguridad personal. 


\section{VICTORIA CALMES}

Como consecuencia de esta crisis de identidad, Andrea recurre a visiones idealizadas de los cuentos de hadas y a sueños de transformaciones en una princesa rubia. Sueña con una transformación física, como una metamorfosis que la convierta en la princesa rubia, bella y encantadora, que nunca había sido en su vida:

Dormida yo me veía corriendo, tropezando, y al golpe sentía que algo se desprendía de mí, como un vestido o una crisálida que se rompe y cac arrugada a los pies. Veía los ojos asombrados de las gentes. Al correr al espejo, contemplaba, temblorosa de emoción, mi transformación asombrosa en una rubia princesa precisamente rubia, como describían los cuentos-, inmediatamente dotada, por gracia de la belleza, con los atributos de dulzura, encanto y bondad, y el maravilloso de esparcir generosamente mis sonrisas (215).

Este idealismo utópico indica la falta de modelos reales de Andrea para identificarse como mujer. La imposibilidad de esta metamorfosis en princesa de cuentos nos trae premoniciones del fracaso posterior que sufriría al enfrentarse a una realidad que está muy lejana a su mundo imaginado de cuentos de hadas.

Ellen Cronan Rose ha estudiado los paradigmas de desarrollo diferentes para los hombres y las mujeres en este tipo de cuentos. Las mujeres tienen un papel más pasivo, de sacrificio a la espera del príncipe encantado que las rescate. Después de la boda con el príncipe, las mujeres-princesas deben vivir felices para siempre (210). Cronan Rose indica los peligros de estas identificaciones míticas: «Women have to recognize that neither in fairy tales nor in other patriarchal texts can we find true images of ourselves» [Las mujeres tenemos que darnos cuenta que ni en los cuentos de hadas ni en otros textos patriarcales podemos encontrar imágenes verdaderas de nosotras mismas] (211). Andrea no puede encontrar una versión realista de su situación como mujer adolescente en esos sueños idealizados que subconscientemente esperaba ver realizados.

Durante toda la novela el sentido de narración subjetivizante es constante, dando al lector la impresión de estar leyendo un diario de una experiencia profundamente femenina. En algunas partes de la novela, esta impresión se hace incluso más evidente, mostrando un tipo de subjetividad esencialmente femenina:

No había nada más que decir al llegar a cste punto, puesto que era fácil para mí entender este idioma de sangre, dolor y creación que empieza con la misma sustancia física cuando se es mujer. Era fácil entenderlo sabiendo mi propio cuerpo preparado -como cargado de semillas- para esta labor de continuación de la vida. Aunque todo en mí era entonces ácido e incompleto como la esperanza, yo lo entendía (240).

Hélène Cixous ha señalado la función esencialmente femenina de la maternidad y la identifica con la escritura femenina, enfatizando el poder de creación. Para Cixous, el proceso del embarazo y de la maternidad supone una diferencia biológica y sexual entre el hombre y la mujer, lo que constituye una característica esencial en el proceso de la creación de la cscritura femenina :

That part of you that leaves a space between yourself and urges you to inscribe in language your woman's style. In women there is always more or less of the mother who makes everything all right, who nourishes, and who stands up against separation; a force that will not be cut off but will knock the wind out of the codes. We will rethink womankind beginning with every form and every period of her body.

IEsa parte de ti que deja un espacio entre ti mismo/a te obliga a inscribir en el lenguaje tu estilo de mujer. Fn las mujeres siempre hay más o menos de la madre que hace todo bien, que cuida y que se opone a la separación; una fuerza que no será cortada sino que vencerá al viento de los códigos. Volveremos a considerar a las mujeres empezando con cada forma y cada periodo de su cuerpo] (883).

4.- Juan Villegas en su artículo "Nada de Carmen Laforet, o la infantilización de la aventura legendaria" ha analizado un baile al que asiste Andrea como el cuento de la Cenicienta al revés, en el que el zapatito de cristal del cuento se convierte en los zapatos sucios y viejos que van a ser la causa de la destrucción de todos los sueños e ilusiones que Andrea tenía como «princesa rubia de cuentos de hadas» (196). Virginia Higginbotham analiza los aspectos del cuento de hadas en la novela, pero con un final negativo en "Nada and the Cinderella Syndrome" (20). 


\section{LA AUSENCIA DE LA MADRE Y LA ASERSIÓN DE LA SUBJETIVIDAD}

El personaje de Andrea, aunque aparece privado de la figura de la madre, reconoce este idioma o lenguaje de su cuerpo femenino, preparado para la maternidad, representada simbólicamente con la imagen de su cuerpo "cargado de semillas". La narradora cuenta sus propias vivencias del pasado en una época difícil de su experiencia como mujer adolescente, intentando encontrar su sitio en el mundo negativo y desalentador que la rodea.

En la novela Nada la búsqueda de identidad y de emancipación de Andrea ha estado originada en principio por la falta de la madre, que es un tema central en el desarrollo del personaje principal. Debido a la ausencia de lo maternal y a su condición de huérfana, Andrea ha buscado modelos que seguir y con los que encontrar una identificación positiva. Sin embargo, la búsqueda de modelos y la añoranza del "paraíso" de lo maternal se ha visto dificultada con la situación de "infierno" que encuentra en Barcelona.

Andrea ha experimentado el ambiente hostil y represivo de la guerra y de la posguerra españolas durante su estancia en Barcelona. La ausencia de la madre representa simbólicamente el estado de abandono, de falta de dirección y de incertidumbre de la época. La protagonista reelabora estos hechos en una mirada retrospectiva al pasado mediante la memoria; recordando y redimiendo un tiempo perdido, que ha constituido un período clave en su proceso de crecimiento y de asersión de su subjetividad como adolescente y como mujer.

\section{BIBLIOGRAFÍA DE OBRAS CITADAS}

Andreu, Alicia G. "Huellas textuales en el bildungsroman de Andrea". Revista de Literatura. 59:118 (1997): 595-605.

Chodorow, Nancy. The Reproduction of Mothering: Psychoanalysis and the Sociology of Gender. Berkeley: U. of California P., 1987.

Cixous, Hélène. "The Laugh of the Medusa". Translated by Keith Cohen and Paula Cohen. Signs 1, 4 (1976): 875-93.

Collins, Marsha. "Carmen Laforet's Nada: Fictional Form and Search of Identity". Symposium: A Quarterly Journal in Modern Foreign Literatures. 38.4 (1984-5): 298-310.

Dolgin Casado, Stacey. "Structure as Meaning in Carmen Laforet's Nada: A Case of SelfCensorship". Studies in Honor of Gilberto Paolini. Newark: Tibbitts, 1996.

Edelman, Hope. Motherless Daughters: The Legacy of Loss. Reading: Addison-Wesley, 1994.

Higginbotham, Virginia. "Nada and the Cinderella Syndrome". Rendezvous: Journal of Arts and Letters. 22.2 (1986): 17-25.

Johnson, Roberta. Carmen Laforet. Madrid: Editorial Gredos, 1971.

Jordan, Barry. "Shifting Generic Boundaries: The Role of Confession and Desire in Laforet's Nada". Neophilologus, 77 (July 1993): 411-22.

— "Narrators, Readers and Writers in Laforet's Nada". Revista Hispánica Moderna, 46: 1 (June 1993): 87-102.

"Laforet's Nada as a Female Bildung?". Symposium: A Quarterly Journal in Modern Foreign Literatures, 46.2 (1992): 105-18.

Kronik, John W. "Nada y el texto asfixiado: Proyección de una estética". Revista Iberoamericana, 47, 114-17 (1981): 195-202.

Laforet, Carmen. Nada. Barcelona: Destinolibro, 1990.

Ordóñez, Elizabeth. "Nada: Initiation into Bourgueois Patriarchy". The Analysis of Hispanic 


\section{VICTORIA CALMES}

Texts: Current Trends in Methodology: Second York College Colloquium. Ed. Lisa E. David and Isabel C. Tarán. Jamaica: Bilingual Press, 1976: 61-78.

Petrea, Mariana. "La promesa del futuro: La dialéctica de la emancipación femenina en Nada de Carmen Laforet”. Letras Femeninas. 20:1-2 (1994): 71-86.

Rose, Ellen Cronan. "Through the Looking Glass: When Women Tell Fairy Tales". The Voyage In: Fictions of Female Development. Ed. Elizabeth Abel, Marianne Hirsch and Elizabeth Langland. Hanover, U. P. of New England, 1983: 209-227.

Spires, Robert C. "Nada y la paradoja de los signos negativos". Siglo XX, 3:1-2 (1985-6): 31-33.

Thomas, Michael. "Symbolic Portals in Laforet's Nada". Revista Hispánica Moderna, 32 (1996): 43-55.

Villegas, Juan. "Nada de Carmen Laforet, o la infantilización de la aventura legendaria". La estructura mítica del héroe en la novela del siglo XX. Barcelona: Planeta, 1973. 